Article

\title{
Defining Elimination of Genital Warts-A Modified Delphi Study
}

\author{
Laila Khawar 1,*®D, Dorothy A. Machalek ${ }^{1,2,3}$, David G. Regan ${ }^{1}\left(\mathbb{D}\right.$, Basil Donovan ${ }^{1,4}$, \\ Skye McGregor ${ }^{1,+}$ and Rebecca J. Guy ${ }^{1,+}$
}

1 The Kirby Institute, UNSW Sydney, Sydney, NSW 2052, Australia; dmachalek@kirby.unsw.edu.au (D.A.M.); Dregan@kirby.unsw.edu.au (D.G.R.); Bdonovan@kirby.unsw.edu.au (B.D.);

Smcgregor@kirby.unsw.edu.au (S.M.); Rguy@kirby.unsw.edu.au (R.J.G.)

2 Centre for Women's Infectious Diseases, the Royal Women's Hospital, Parkville, VIC 3052, Australia

3 School of Population and Global Health, University of Melbourne, Parkville, VIC 3053, Australia

4 Sydney Sexual Health Centre, Sydney Hospital, Sydney, NSW 2000, Australia

* Correspondence: lkhawar@kirby.unsw.edu.au

+ Co-last authorship.

Received: 27 May 2020; Accepted: 16 June 2020; Published: 18 June 2020

\begin{abstract}
Background: Substantial declines in genital warts (GW) have been observed in countries with quadrivalent HPV vaccination programmes, with Australia showing the highest reductions due to early commencement and high vaccination coverage. There is a real potential to achieve GW elimination; however, no GW elimination definition exists. Taking Australia as a case study, we aimed to reach expert consensus on a proposed GW elimination definition using a modified Delphi process. Method: We used modelling and epidemiological data to estimate the expected number of new GW cases, from pre-vaccination (baseline) in 2006 to the year 2060 in Australian heterosexuals, men who have sex with men (MSM), and newly arrived international travellers and migrants. We used these data and the literature, to develop a questionnaire containing ten elimination-related items, each with 9-point Likert scales (1—-strongly disagree; 9-strongly agree). The survey was completed by 18 experts who participated in a full day face-to-face modified Delphi study, in which individuals and then small groups discussed and scored each item. The process was repeated online for items where consensus ( $\geq 70 \%$ agreement) was not initially achieved. Median and coefficient of variation $(\mathrm{COV})$ were used to describe the central tendency and variability of responses, respectively. Findings: There was a $95 \%$ participation rate in the face-to-face session, and $84 \%$ response rate in the final online round. The median item score ranged between 7.0 and 9.0 and the COV was $\leq 0.30$ on all items. Consensus was reached that at $\geq 80 \% \mathrm{HPV}$ vaccination coverage, GW will be eliminated as a public health problem in Australia by 2060. During this time period there will be a $95 \%$ reduction in population-level incidence compared with baseline, equivalent to $<1 \mathrm{GW}$ case per 10,000 population. The reductions will occur most rapidly in Australian heterosexuals, with $73 \%, 90 \%$ and $97 \%$ relative reductions by years 2021, 2030 and 2060, respectively. The proportion of new GW cases attributable to importation will increase from $3.6 \%$ in 2006 to $49 \%$ in 2060. Interpretation: Our results indicate that the vaccination programme will minimise new GW cases in the Australian population, but importation of cases will continue. This is the first study to define GW elimination at a national level. The framework developed could be used to define GW elimination in other countries, with thresholds particularly valuable for vaccination programme impact evaluation. Funding: LK supported through an Australian Government Research Training Programme Scholarship; unconditional funding from Seqirus to support the Delphi Workshop.
\end{abstract}


Keywords: human papillomavirus HPV; quadrivalent HPV vaccine; nonavalent HPV vaccine; 9-valent vaccine; genital warts; elimination; Australia's HPV vaccination programme; elimination target; elimination as a public health problem; Delphi study

\section{Introduction}

Human papillomavirus (HPV) is the most common sexually transmissible infection (STI) globally, and is associated with significant morbidity and mortality due to genital warts (GW), and anogenital and other cancers $[1,2]$. Three HPV vaccines are currently available, the bivalent $(b \mathrm{HPV})$, quadrivalent $(q \mathrm{HPV})$ and nonavalent $(n \mathrm{HPV})$ vaccines [3]. All three vaccines provide protection against the high-risk HPV types $16 / 18$ that are responsible for over $70 \%$ of cervical cancers [3]. The $q \mathrm{HPV}$ and $n \mathrm{HPV}$ vaccines also provide protection against low-risk HPV types 6/11 that cause more than 95\% of GW [4], while the $n \mathrm{HPV}$ vaccine prevents infection for five additional cancer-causing types $(31,33,45,52$ and 58) [3]. Over 80 countries have introduced an HPV vaccination programme, and the majority of these use the $q \mathrm{HPV}$ or $n \mathrm{HPV}$ vaccines. In 2018 , the $q \mathrm{HPV}$ and $n \mathrm{HPV}$ vaccine together comprised $\sim 77 \%$ of the total vaccine doses delivered globally [5].

The primary aim of HPV vaccination is to prevent cervical cancer, which is associated with high global mortality and morbidity [6]. In 2018, the World Health Organization (WHO) called for working toward the ambitious goal of eliminating cervical cancer as a public health problem [7]. Furthermore, in its Global Health Sector Strategy on STIs, the WHO highlights the importance of vaccination to achieve the elimination of GW and encourages countries to define national GW elimination targets [8]. Since the commencement of $q \mathrm{HPV} / n \mathrm{HPV}$ vaccination, substantial reductions in $\mathrm{GW}$ have been observed in many countries [9], suggesting real potential for GW elimination. Notably, Australia, where a national programme commenced in 2007 for girls and 2013 for boys [10,11], has within a decade achieved 96\% and $88 \%$ reductions in new GW diagnoses among young vaccine-eligible Australian-born women and heterosexual men attending sexual health clinics, respectively [12]. Australia is likely to be the first country to reach GW elimination; however, in terms of defining elimination, several points remain uncertain.

First, there is no standardised definition of GW elimination. The WHO broadly defines elimination of an infection or infectious disease under two categories: (i) interruption of transmission of an infection, defined as reduction to zero of the incidence of infection in a defined geographical area [13] and (ii) elimination as a public health problem, defined as achievement of measurable global targets set by the WHO [13]. It is unclear which of these elimination concepts is suitable for GW. Second, published modelling studies of GW elimination did not account for the potential impact of importation and spread of HPV 6/11 by people born overseas [14-16]. Third, there are uncertainties around the impact of GW cases caused by other non-vaccine HPV types on ongoing GW cases and the mechanisms by which this can be measured $[17,18]$. Finally, measuring elimination ideally requires a sustainable system to measure both incidence and the burden of disease including prevalence, and the associated morbidity and financial cost. Taking Australia as a case study, we conducted a modified Delphi study, firstly to reach expert consensus on how elimination should be defined and measured, and secondly, to develop GW control and elimination thresholds.

\section{Method}

\subsection{The Delphi Method}

The Delphi method has been widely used in public health to reach consensus among a group of experts in a specific subject area. In situations where available information is contradictory or insufficient, the Delphi method provides an effective tool to make decisions [19]. The method involves a structured multilevel-iterative process with a group of experts, where each iteration uses feedback 
from the preceding rounds. A conventional Delphi process entails four essential elements of iteration, anonymity, controlled feedback, and assessment of group judgement that provides an opportunity for the participants to revise their views [20]. This process continues until no further significant changes occur between rounds and a group consensus is achieved. The group Delphi study, otherwise known as an expert workshop, is a variation of the conventional Delphi method [20]. It preserves all the elements of a conventional Delphi except for anonymity, which is compromised to expedite the consensus-forming process.

\subsection{Design and Participants}

We designed a modified Delphi study (Figure 1) comprising a two-round face-to-face Delphi workshop with a group of national and international experts followed by an online round. Experts were selected using a purposive sampling technique to represent epidemiological, clinical, mathematical modelling, statistics, and health policy related expertise in HPV and other STIs.

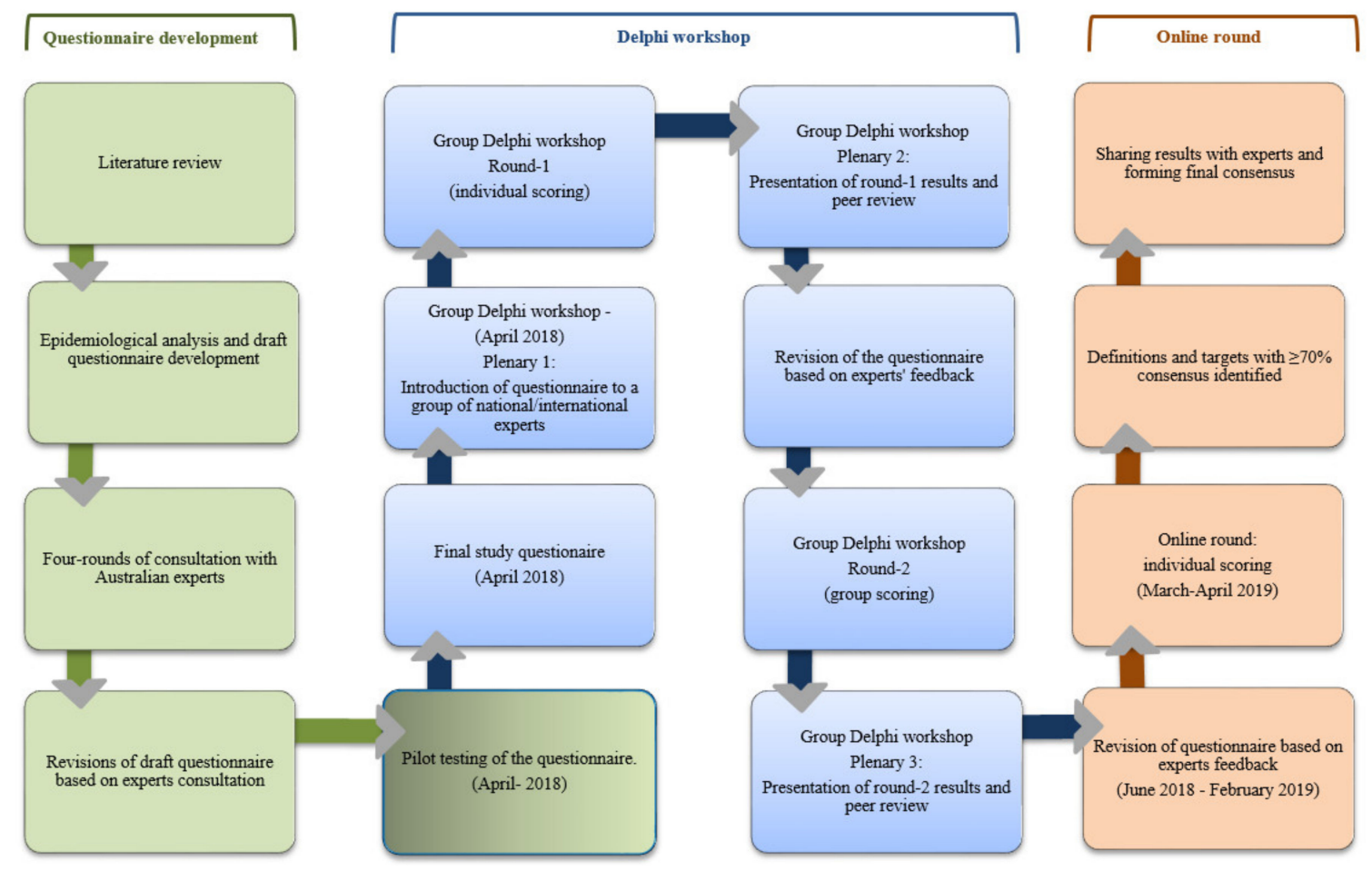

Figure 1. Flowchart of the process for development of consensus.

\subsection{Procedures}

\subsubsection{Epidemiological Analyses}

We first conducted a review of the literature (peer-reviewed and grey literature) and held extensive consultations with six Australian experts. Extending our previous work [14,15], we estimated the number of new GW cases among Australian heterosexuals and MSM, plus newly arrived international travellers, using epidemiological and modelling data at the baseline of 2006 . The parameters included were population size, baseline GW incidence, sexual behaviour and mixing, and vaccination coverage in Australia and the home countries of international travellers [15,21-27]. Population size projection, population-specific GW incidence, and modelled relative reductions in GW due to vaccination were calculated for the years 2021, 2030 and 2060, based on the timepoints presented in our previous research [14]. This led to the development of a proposed elimination threshold for GW for the year 2060. In addition, we also proposed two disease-control related thresholds for the years 2021 and 2030 to monitor the trajectory towards GW elimination (Table 1). The background calculations 
for the proposed thresholds are shown in Supplementary Information Part 1-see Supplementary Tables S1-S12.

Table 1. Estimates presented at the Delphi workshop for number and relative reduction in new genital warts cases in Australia (consolidated cases including Australian residents and international travellers).

\begin{tabular}{|c|c|c|c|c|c|c|c|}
\hline & \multirow{2}{*}{$\begin{array}{l}\text { Australian } \\
\text { Population }\end{array}$} & \multicolumn{4}{|c|}{ New Genital Warts Cases- $n(95 \%$ CI) } & \multirow{2}{*}{$\begin{array}{c}\text { Rate Per } \\
10,000 \\
\text { Persons }\end{array}$} & \multirow{2}{*}{$\begin{array}{c}\begin{array}{c}\text { Relative } \\
\text { Reduction } \\
(\%)\end{array} \\
\text { in New } \\
\text { Genital } \\
\text { Warts }\end{array}$} \\
\hline & & & & & & & \\
\hline & & International & $\begin{array}{c}\text { Australian } \\
\text { Heterosexual }\end{array}$ & $\begin{array}{l}\text { Australian } \\
\text { MSM }\end{array}$ & $\begin{array}{c}\text { Consolidated } \\
\text { Cases }\end{array}$ & & $\begin{array}{c}\text { from } \\
\text { Baseline } \\
\text { (95\% CI) }\end{array}$ \\
\hline & & Travellers & Population & Population & & & \\
\hline $\begin{array}{l}\text { Baseline } \\
(2006)\end{array}$ & $20,091,504$ & $\begin{array}{c}1562 \\
(1428-1707)\end{array}$ & $\begin{array}{c}36,719 \\
(31,579-42,181)\end{array}$ & $\begin{array}{c}5656 \\
(5512-5803)\end{array}$ & $\begin{array}{c}43,937 \\
(38,519-49,691)\end{array}$ & $\begin{array}{c}21.9 \\
(19.2-24.7)\end{array}$ & $\cdot$. \\
\hline 2021 & $26,110,176$ & $\begin{array}{c}1634 \\
(1492-1788)\end{array}$ & $\begin{array}{c}10,419 \\
(9849-13,155)\end{array}$ & $\begin{array}{c}6593 \\
(6437-6752)\end{array}$ & $\begin{array}{c}18,647 \\
(17,777-21,695)\end{array}$ & $7.1(6.8-8.3)$ & $\begin{array}{c}67.3 \\
(66.8-67.9)\end{array}$ \\
\hline 2030 & $29,748,172$ & $\begin{array}{c}1364 \\
(1232-1510)\end{array}$ & $\begin{array}{c}5012 \\
(4350-5811)\end{array}$ & $\begin{array}{c}5034 \\
(4897-5174)\end{array}$ & $\begin{array}{c}11,410 \\
(10,479-12,494)\end{array}$ & $3.8(3.5-4.2)$ & $\begin{array}{c}82.4 \\
(82.1-82.8)\end{array}$ \\
\hline 2060 & $40,703,739$ & $\begin{array}{c}2280 \\
(2110-2462)\end{array}$ & $\begin{array}{c}2162 \\
(1876-2506)\end{array}$ & $\begin{array}{c}216 \\
(188-247)\end{array}$ & $\begin{array}{c}4658 \\
(4174-5215)\end{array}$ & $1.1(1.0-1.3)$ & $\begin{array}{c}94.7 \\
(94.6-94.9)\end{array}$ \\
\hline
\end{tabular}

Estimates calculated without accounting for new genital warts cases attributable to non-vaccine type HPV infection and the chains of transmission in Australia due to importation of genital warts. (..) $=$ not applicable.

\subsubsection{Questionnaire Development}

The epidemiological analyses resulted in the development of a questionnaire containing preliminary GW elimination definitions and thresholds. The questionnaire was tested in a small pilot Delphi with eight early- to mid-career level researchers to ensure the clarity and acceptability of the items. An eight-item questionnaire (see Supplementary Table S13 for details) was then administered in the Delphi workshop. Subsequently, the questionnaire was revised based on experts' feedback at the end of each round of the study and more items were added accordingly.

\subsubsection{Delphi Workshop}

Prior to the workshop, experts were sent a document explaining the aims of the study and the methods used for calculation of the proposed thresholds. The workshop began with a plenary session where the questionnaire and the process of reaching consensus was introduced. In round 1, experts were asked to score items individually in terms of their agreement on a 9-point Likert scale, with 1 being strongly disagree, and 9 being strongly agree. Experts were also asked to provide qualitative feedback on each item. All responses were treated anonymously, and therefore even when the participants were known to one another, their opinions remained unidentifiable to the group.

In round 2, experts were divided into four small groups of 4-5 people and asked to score their agreement or disagreement as a group to help consolidate opinions in a short time period. Each group was also asked to provide qualitative feedback to justify their viewpoint. Results were presented during plenary sessions after each round. Convergence and deviation of opinions were brought forward in the plenary sessions and groups were asked to justify any conflicting opinions for discussion with the whole group. 


\subsubsection{On-Line Round}

Items that did not reach consensus at the workshop were revised based on experts' feedback. A detailed document explaining the revised items was then distributed via email. A weblink to a survey was provided and experts were asked to score the revised items.

\subsection{Data Analysis and Level of Consensus}

Median and mean were used to describe the central tendency, and coefficient of variation (COV) and interquartile ranges were used to describe the variability of expert responses on each item. Items were excluded from the subsequent round if $\geq 70 \%$ of participants scored the item $\leq 4$ in the preceding round with a COV of $\leq 0.5$. Items met consensus for inclusion if $\geq 70 \%$ of participants scored the item $\geq 7$ in the preceding round with a COV of $\leq 0.5$. If items failed to meet the inclusion/exclusion criteria in the preceding round, they were modified as per the feedback for the successive round. A response rate of $80 \%$ for each round of the study was considered sufficient.

\subsection{Ethics Approval}

Ethical approval was obtained from the UNSW Human Research Ethics Advisory Panel (reference number HC16530). All experts were provided with a participation information sheet. Consent was obtained prior to their participation in the workshop.

\subsection{Role of Funding Source}

The sponsor had no role in study design, data collection, analysis, interpretation or writing of the report. The corresponding author has full access to all the data and had full responsibility to submit for publication.

\section{Results}

\subsection{Characteristics of the Experts}

We invited 21 experts to participate in the study, of whom 19 agreed. Of these, 18 participated in the workshop (95\%), and 16 participated in the online round (84\%). The characteristics of the experts are shown in Table 2. The Delphi participants were mostly female, senior academics and from a range of disciplines (Table 2).

Table 2. Characteristics of experts who completed the Delphi workshop and the online round.

\begin{tabular}{ccc}
\hline & Delphi Workshop $(\boldsymbol{n = 1 8 )}$ & Online Round $(n=\mathbf{1 6})$ \\
\hline Gender & & \\
\hline Female & $72 \%$ & $69 \%$ \\
Male & $28 \%$ & $31 \%$ \\
\hline Age group & & \\
\hline$\leq 35$ years & $11 \%$ & $13 \%$ \\
$35-44$ years & $22 \%$ & $25 \%$ \\
$45-54$ years & $50 \%$ & $50 \%$ \\
$\geq 55$ years & $17 \%$ & $13 \%$ \\
\hline Education & & \\
\hline Masters & $6 \%$ & $6 \%$ \\
Medical degree & $11 \%$ & $6 \%$ \\
PhD & $83 \%$ & $88 \%$ \\
\hline
\end{tabular}


Table 2. Cont.

\begin{tabular}{ccc}
\hline & Delphi Workshop $(n=\mathbf{1 8})$ & Online Round $(\boldsymbol{n}=\mathbf{1 6})$ \\
\hline Professional level & & \\
\hline Professional (non-academic) & $11 \%$ & $6 \%$ \\
Early-/mid-career academic & $22 \%$ & $25 \%$ \\
Senior academic & $67 \%$ & $69 \%$ \\
\hline Expertise & & \\
\hline Health policy & $6 \%$ & $6 \%$ \\
Statistics & $6 \%$ & $6 \%$ \\
Mathematical modelling & $22 \%$ & $25 \%$ \\
Vaccination/immunology & $22 \%$ & $13 \%$ \\
Epidemiology & $22 \%$ & $25 \%$ \\
Clinical and epidemiology & $17 \%$ & $19 \%$ \\
Other & $6 \%$ & $6 \%$ \\
\hline
\end{tabular}

\subsection{Results of Delphi Rounds 1-3}

\subsubsection{Conceptual Definitions (Items 1 and 2)}

At the end of the workshop, two of four groups of experts scored the concept of interruption of endemic transmission of HPV 6/11 $\leq 4$ (median:4.5; COV: 0.65) (Table 3). Two conflicting themes emerged, evident by a large COV. According to one group, this was an ambitious goal which would be very difficult to measure. They emphasized that measuring elimination using this definition is predicated on the ability to differentiate between cases attributable to local strains circulating in the community (endemic) versus imported cases. The opposing group argued that interruption of endemic transmission of HPV 6/11 was an aspirational goal necessary to promote vaccine coverage. After the workshop, we reviewed the relevant literature, which indicated that discrete geographical variations of HPV 6/11 subtypes do not exist, therefore distinguishing between endemic and imported cases through genotyping is not possible (Supplementary Information Part 2, Item 1). A revised item was presented in the online round, with consensus reached that interruption of endemic HPV 6/11 transmission is not a feasible elimination definition (median 7.0; COV, 0.20) (Table 4).

Table 3. Questionnaire and results of round 2 of the Delphi face-to-face workshop.

\begin{tabular}{|c|c|c|c|c|c|}
\hline $\begin{array}{l}\text { Revised Items for Round } 2 \text { of the Delphi } \\
\text { Workshop }\end{array}$ & Median & Mean & $\begin{array}{c}\% \\
\text { Agreement }\end{array}$ & $\begin{array}{c}\% \\
\text { Disagreement }\end{array}$ & Outcome \\
\hline & (IQR) & $(\mathrm{COV})$ & $\begin{array}{l}\text { (Scores 7,8 } \\
\quad \& 9)\end{array}$ & $\begin{array}{l}\text { (Scores 1,2,3 } \\
\text { \& 4) }\end{array}$ & \\
\hline \multicolumn{6}{|c|}{ Section-1: Conceptual definitions } \\
\hline $\begin{array}{l}\text { Item-1: Elimination of (endemic) } \\
\text { transmission: Interruption of endemic genital } \\
\text { warts transmission caused by HPV } 6 \text { and 11, } \\
\text { and limited transmission from imported cases. }\end{array}$ & $\begin{array}{c}4.5 \\
(2.5-6.3)\end{array}$ & $\begin{array}{c}4.3 \\
(0.65)\end{array}$ & $25 \%$ & $50 \%$ & $\begin{array}{l}\text { To revise item } \\
\text { as per } \\
\text { experts' } \\
\text { feedback }\end{array}$ \\
\hline $\begin{array}{l}\text { Item-2: Elimination as a public health } \\
\text { problem: Transmission of genital warts } \\
\text { continues to occur (even in absence of } \\
\text { importation) but is reduced to a level that it } \\
\text { does not constitute a public health problem. }\end{array}$ & $\begin{array}{c}6.5 \\
(5.5-7.5)\end{array}$ & $\begin{array}{c}6.7 \\
(0.31)\end{array}$ & $50 \%$ & $25 \%$ & $\begin{array}{l}\text { To revise item } \\
\text { as per } \\
\text { experts' } \\
\text { feedback }\end{array}$ \\
\hline
\end{tabular}


Table 3. Cont

\begin{tabular}{|c|c|c|c|c|c|}
\hline $\begin{array}{l}\text { Revised Items for Round } 2 \text { of the Delphi } \\
\text { Workshop }\end{array}$ & Median & Mean & $\begin{array}{c}\% \\
\text { Agreement }\end{array}$ & $\begin{array}{c}\% \\
\text { Disagreement }\end{array}$ & Outcome \\
\hline & (IQR) & $(\mathrm{COV})$ & $\begin{array}{l}\text { (Scores } 7,8 \\
\quad \& 9)\end{array}$ & $\begin{array}{l}\text { (Scores } 1,2,3 \\
\quad \& 4)\end{array}$ & \\
\hline \multicolumn{6}{|c|}{ Section-2: Operational thresholds } \\
\hline $\begin{array}{l}\text { Short-term control threshold: } \leq 4 \text { cases per } 10,000 \\
\text { population by year 2030; Equivalent to: } \\
\text { A reduction in annual genital warts incidence by } \\
82 \% \text { by year } \\
2030 \\
\text { Long-term elimination threshold: } \leq 1 \text { case per } \\
10,000 \text { population by year } 2060 ; \text { Equivalent to: } \\
\text { A reduction } \\
\text { in annual genital warts incidence by } 95 \% \text { by year } \\
2060\end{array}$ & .. & .. &.. &.. & $\cdot \cdot$ \\
\hline $\begin{array}{l}\text { Item 3: The proportion of genital warts caused } \\
\text { by non-vaccine HPV types will have an impact } \\
\text { on the control threshold in year } 2030\end{array}$ & $\begin{array}{c}2.5 \\
(1.7-4.2)\end{array}$ & $\begin{array}{c}3.5 \\
(0.89)\end{array}$ & $25 \%$ & $75 \%$ & $\begin{array}{l}\text { To revise item } \\
\text { as per } \\
\text { experts' } \\
\text { feedback }\end{array}$ \\
\hline $\begin{array}{l}\text { Item 4: Ongoing transmission of genital warts } \\
\text { in Australia due to importation would have an } \\
\text { impact on the control threshold in year } 2030\end{array}$ & $\begin{array}{c}3.5 \\
(1.7-5.5)\end{array}$ & $\begin{array}{c}3.8 \\
(0.70)\end{array}$ & $25 \%$ & $50 \%$ & $\begin{array}{l}\text { To revise item } \\
\text { as per } \\
\text { experts' } \\
\text { feedback }\end{array}$ \\
\hline $\begin{array}{l}\text { Item 5: The proportion of genital warts caused } \\
\text { by non-vaccine HPV types will have an impact } \\
\text { on the elimination threshold in year } 2060\end{array}$ & $\begin{array}{c}6.0 \\
(4.2-7.5)\end{array}$ & $\begin{array}{c}5.8 \\
(0.52)\end{array}$ & $50 \%$ & $25 \%$ & $\begin{array}{l}\text { To revise item } \\
\text { as per } \\
\text { experts' } \\
\text { feedback }\end{array}$ \\
\hline $\begin{array}{l}\text { Item 6: Ongoing transmission of genital warts } \\
\text { in Australia due to importation would have an } \\
\text { impact on the elimination threshold in year } \\
2060\end{array}$ & $\begin{array}{l}3.5 \\
(1.7-5.7)\end{array}$ & $\begin{array}{c}4.0 \\
(0.79)\end{array}$ & $25 \%$ & $50 \%$ & $\begin{array}{l}\text { To revise item } \\
\text { as per } \\
\text { experts' } \\
\text { feedback }\end{array}$ \\
\hline \multicolumn{6}{|c|}{ Section-3 Intervention coverage/Process threshold } \\
\hline $\begin{array}{l}\text { Item } 7 \text { : Completion of HPV vaccination course } \\
\text { is equal to or greater than } 80 \% \text { coverage in } \\
\text { the target population }\end{array}$ & $\begin{array}{c}8.0 \\
(7.5-8.2)\end{array}$ & $\begin{array}{c}7.8 \\
(0.16)\end{array}$ & $75 \%$ & & $\begin{array}{l}\text { Consensus } \\
\text { met- } \\
\text { accept }\end{array}$ \\
\hline \multicolumn{6}{|c|}{ Section-4: Measuring elimination } \\
\hline $\begin{array}{l}\text { Item 8: There needs to be measurement of } \\
\text { genital warts from both general practice and } \\
\text { sexual health clinics }\end{array}$ & $\begin{array}{c}9.0 \\
(8.2-9.0)\end{array}$ & $\begin{array}{c}8.3 \\
(0.18)\end{array}$ & $75 \%$ & .. & $\begin{array}{l}\text { Consensus } \\
\text { met- } \\
\text { accept }\end{array}$ \\
\hline $\begin{array}{l}\text { Item } 9 \text { (new item): Measurement should also } \\
\text { include genotyping of genital warts }\end{array}$ & $\begin{array}{c}8.0 \\
(7.0-9.0)\end{array}$ & $\begin{array}{c}8.0 \\
(0.14)\end{array}$ & $100 \%$ & .. & $\begin{array}{l}\text { Consensus } \\
\text { met- } \\
\text { accept }\end{array}$ \\
\hline
\end{tabular}

(..) $=$ not applicable. 
Table 4. Questionnaire and results of the third online round.

\begin{tabular}{|c|c|c|c|c|c|}
\hline Revised Items for the Online Round & Median & Mean & $\begin{array}{c}\% \\
\text { Agreement }\end{array}$ & $\begin{array}{c}\% \\
\text { Disagreement }\end{array}$ & Outcome \\
\hline & (IQR) & $(\mathrm{COV})$ & $\begin{array}{l}\text { (Scores 7,8 } \\
\text { \& 9) }\end{array}$ & $\begin{array}{c}\text { (Scores } 1,2,3 \\
\text { \& } 4)\end{array}$ & \\
\hline \multicolumn{6}{|c|}{ Conceptual definitions } \\
\hline $\begin{array}{l}\text { Item 1: Elimination of (endemic) } \\
\text { transmission: Defining genital warts } \\
\text { elimination as interruption of endemic HPV } 6 \text { \& } \\
11 \text { transmission is not feasible due to a lack of } \\
\text { geographic variation in HPV } 6 \& 11 \text { subtype } \\
\text { distribution }\end{array}$ & $\begin{array}{c}7.0 \\
(7.0-8.0)\end{array}$ & $\begin{array}{c}6.9 \\
(0.20)\end{array}$ & $81 \%$ & $6 \%$ & $\begin{array}{l}\text { Consensus } \\
\text { met- } \\
\text { agreed to } \\
\text { reject }\end{array}$ \\
\hline $\begin{array}{l}\text { Item 2: Elimination as a public health } \\
\text { problem: To reduce the burden of genital warts } \\
\text { to a level where it no longer constitutes a public } \\
\text { health problem }\end{array}$ & $\begin{array}{c}8.0 \\
(7.0-9.0)\end{array}$ & $\begin{array}{c}7.4 \\
(0.20)\end{array}$ & $81 \%$ & $6 \%$ & $\begin{array}{c}\text { Consensus } \\
\text { met- } \\
\text { accept }\end{array}$ \\
\hline
\end{tabular}

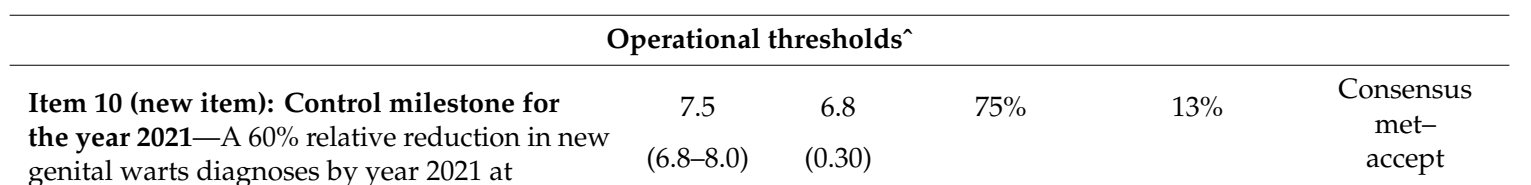

a population level, as compared to the baseline of 2006; Equivalent to: Reduction of new cases

of genital warts to $\leq 9$ cases per 10,000

population by year 2021

\begin{tabular}{|c|c|c|c|c|c|}
\hline $\begin{array}{l}\text { Item } 4^{*} \text { : Control threshold for the year } \\
2030 \text {-An } 80 \% \text { relative reduction since } 2006 \text { in } \\
\text { new genital warts diagnoses by year } 2030 \text { at } \\
\text { a population level, as compared to the baseline } \\
\text { of } 2006 \text {; Equivalent to: Reduction of new cases } \\
\text { of genital warts to } \leq 4 \text { cases per } 10,000 \\
\text { population by year } 2030\end{array}$ & $\begin{array}{c}7.5 \\
(7.0-8.0)\end{array}$ & $\begin{array}{c}6.9 \\
(0.27)\end{array}$ & $81 \%$ & $13 \%$ & $\begin{array}{c}\text { Consensus } \\
\text { met- } \\
\text { accept }\end{array}$ \\
\hline $\begin{array}{l}\text { Item } 6^{*} \text { : Elimination threshold for the year } \\
2060-A \text { A } 95 \% \text { relative reduction since } 2006 \text { in } \\
\text { new genital warts diagnoses by year } 2060 \text { at } \\
\text { a population level, as compared to the baseline } \\
\text { of } 2006 \text { Equivalent to: Reduction of new cases } \\
\text { of genital warts to } \leq 1 \text { case per } 10,000 \\
\text { population by year } 2030\end{array}$ & $\begin{array}{c}7.0 \\
(6.8-8.0)\end{array}$ & $\begin{array}{c}7.0 \\
(0.24)\end{array}$ & $75 \%$ & $6 \%$ & $\begin{array}{c}\text { Consensus } \\
\text { met- } \\
\text { accept }\end{array}$ \\
\hline
\end{tabular}

\footnotetext{
Items 3 and 5 were removed from the online round based on emerging evidence-see Supplementary Information Part 2, Items 3 and 5. * After adjusting for ongoing short chain of transmission of genital warts in Australia due to importation.
}

Similarly, for the concept of elimination as a public health problem, two of the four groups of experts agreed on this definition by scoring it $\geq 7$ (median: 6.5; COV: 0.31) (Table 3). Some participants argued that this is a pragmatic definition, while others maintained that this is not as aspirational as interruption of transmission of infection. Nonetheless, there was general agreement on the need to clarify what constituted a public health problem, and whether GW fulfilled the criteria.

A review of literature was performed post workshop through which it was determined that the reported prevalence of GW in the pre-vaccination era satisfies the essential criteria for classification of a condition as a public health problem (Supplementary Information Part 2, Item 2), and the relevant details were communicated to experts. A revised item was presented in the online round where consensus of $81 \%$ was reached for inclusion (median: 8.0, COV: 0.20) (Table 4). 


\subsubsection{Operational Definitions/Thresholds (Items 3-6 and 10)}

Views were divided on the potential impact of non-vaccine HPV types on the control threshold ( $\leq 4$ cases per 10,000 population by year 2030 , equivalent to $82 \%$ relative reduction from the baseline of 2006) and the elimination threshold ( $\leq 1$ case per 10,000 population by year 2060, equivalent to $95 \%$ relative reduction from the baseline of 2006) at the end of the workshop (Table 3). Some experts considered there to be a need to undertake HPV type surveillance of lesions to answer this question, while others argued that the small proportion of GW attributable to non-vaccine HPV types was unlikely to have an impact on the estimated thresholds. Following the workshop, new evidence was published showing significant cross-protection against non-vaccine HPV types, including a majority of those that cause GW [28] (Supplementary Information Part 2, Items 3 and 5). As the intention of the Delphi process was to address questions where there is an absence of evidence, this new evidence made items 3 and 5 redundant for the online round, and these items were therefore removed from the online round.

Similarly, at the end of the workshop, views were divided regarding the potential impact of ongoing transmission of GW due to importation on the estimated control and elimination thresholds (Table 3). Some experts believed that chains of transmission due to importation could have an impact, and that modelling is required to accurately calculate the HPV 6/11 effective reproductive number $\left(R_{e f f}\right)$. $R_{\text {eff }}$ denotes the average number of secondary cases per infectious case in a population made up of both susceptible and non-susceptible hosts. Other experts argued that the effects could potentially be less than expected due to growing levels of HPV vaccination globally. Nonetheless, experts suggested that perhaps thresholds needed to be adjusted to account for this. The experts also suggested defining an additional control milestone for the year 2021.

Based on the experts' feedback, we conservatively adjusted our proposed control milestone $(\leq 7$ cases per 10,000 population, equivalent to $67 \%$ relative reduction from the baseline of 2006) and control threshold for the years 2021 and 2030, respectively, to account for the effects of chains of transmission due to importation. The relative reductions in new GW diagnoses were changed from $67 \%$ to $60 \%$ for 2021 and from $82 \%$ to $80 \%$ for 2030 (Table 5). The elimination threshold for 2060 ( $\leq 1$ case per 10,000 population, equivalent to $95 \%$ relative reduction from the baseline of 2006), however, was not adjusted. Revised items were presented in the online round. Items 4 and 6 met consensus at $81 \%$ (median 7.5, COV: 0.27 ) and 75\% (median 7.0, COV: 0.24), respectively (Table 4). This signified a convergence of opinion for the 2030 control threshold and 2060 elimination threshold. An additional item on a control milestone for the year 2021 was added as per the feedback and met consensus for inclusion (Table 4).

Table 5. Revised estimates for number and relative reduction in new genital warts consults in Australia, after adjusting for the ongoing transmission due to importation of genital warts (consolidated cases including Australian residents and international travellers).

\begin{tabular}{|c|c|c|c|c|c|c|c|}
\hline & \multirow{3}{*}{$\begin{array}{l}\text { Australian } \\
\text { Population }\end{array}$} & \multicolumn{4}{|c|}{ New GW Cases- $n(95 \%$ CI $)$} & \multirow{3}{*}{$\begin{array}{c}\text { Rate Per 10,000 } \\
\text { Persons }\end{array}$} & \multirow{3}{*}{$\begin{array}{c}\begin{array}{c}\text { Relative } \\
\text { Reduction (\%) }\end{array} \\
\begin{array}{c}\text { in New Genital } \\
\text { Warts from }\end{array} \\
\begin{array}{c}\text { Baseline (95\% } \\
\text { CI) }\end{array}\end{array}$} \\
\hline & & & & & & & \\
\hline & & International & $\begin{array}{c}\text { Australian } \\
\text { Heterosexual }\end{array}$ & $\begin{array}{c}\text { Australian } \\
\text { MSM }\end{array}$ & Consolidated & & \\
\hline & & Travellers & Population & Population & & & \\
\hline $\begin{array}{l}\text { Baseline } \\
(2006)\end{array}$ & $20,091,504$ & $\begin{array}{c}1,562 \\
(1,428-1,707)\end{array}$ & $\begin{array}{c}36,719 \\
(31,579-42,181)\end{array}$ & $\begin{array}{c}5656 \\
(5512-5803)\end{array}$ & $\begin{array}{c}43,937 \\
(38,519-49,691)\end{array}$ & 21.9 (19.2-24.7) & .. \\
\hline 2021 & $26,110,176$ & $\begin{array}{c}2007 \\
(1849-2177)\end{array}$ & $\begin{array}{c}12,796 \\
(11,255-15,034)\end{array}$ & $\begin{array}{c}8097 \\
(7924-8072)\end{array}$ & $\begin{array}{c}22,900 \\
(21,029-25,483)\end{array}$ & $8.8(8.1-9.8)$ & $59.9(59.2-60.5)$ \\
\hline 2030 & $29,748,172$ & $\begin{array}{c}1518 \\
(1377-1670)\end{array}$ & $\begin{array}{c}5578 \\
(5037-6728)\end{array}$ & $\begin{array}{c}5603 \\
(5459-5750)\end{array}$ & $\begin{array}{c}12,700 \\
(11,873-14,149)\end{array}$ & $4.3(4.0-4.8)$ & $80.4(80.1-80.9)$ \\
\hline 2060 & $40,703,739$ & $\begin{array}{c}2280 \\
(2110-2462)\end{array}$ & $\begin{array}{c}2162 \\
(1876-2506)\end{array}$ & $\begin{array}{c}216 \\
(188-247)\end{array}$ & $\begin{array}{c}4658 \\
(4174-5215)\end{array}$ & $1.1(1.0-1.3)$ & $94.8(94.6-94.9)$ \\
\hline
\end{tabular}

(..) = not applicable. 


\subsubsection{Intervention-Coverage (Item 7)}

In round 2, experts suggested rewording the item relating to vaccination coverage to reflect completion of HPV vaccination course rather than two dose completion, as two dose coverage (0-2 months apart) for the $q \mathrm{HPV}$ vaccine schedule may be different from two dose coverage (0-6 months apart) for the $n \mathrm{HPV}$ vaccine, which replaced the $q \mathrm{HPV}$ vaccine in the national HPV vaccination programme in Australia in 2018. At the end of round 2, the reworded item met consensus for inclusion at 75\% (median 8.0, COV: 0.16) (Table 3).

\subsubsection{Elimination Measurement (Items 8 and 9)}

At the end of round 1, most experts disagreed with using sexual health clinics as the main data source for measuring GW elimination and suggested that both general practice and sexual health clinic data should be used, the two out-patient healthcare settings in Australia where GW episodes are seen. The revised item, including both data sources, met consensus for inclusion at 75\% (median 9.0; COV 0.18) (Table 3). Experts also suggested an additional item on genotyping of GW. Therefore, a new item was added in round 2, indicating that measurement should include genotyping of GW to better understand the aetiology of remaining warts, which reached unanimous consensus (median 8.0; COV 0.14) (Table 3).

\subsubsection{Revised Background Calculations}

After adjusting for ongoing transmission due to importation, our background calculations to inform these thresholds showed that the fastest reductions will occur in Australian resident heterosexuals, with $\sim 73 \%, \sim 90 \%$ and $\sim 97 \%$ relative reduction by years 2021, 2030 and 2060, respectively (Figure 2). Reductions in MSM will be slower initially, with a slight increase by 2021, followed by a $\sim 37 \%$ and $\sim 99 \%$ relative reduction by the years 2030 and 2060, respectively. Our analyses also demonstrated that the proportion of all new GW cases in Australia attributable to importation will increase from $36 \%$ in 2006 to $49 \%$ in 2060 (Figure 3). The relative reduction in new GW diagnoses in international travellers will vary depending on the vaccination coverage in their home countries. As a majority (78\%) of backpackers are from countries with a $q \mathrm{HPV} / n \mathrm{HPV}$ vaccination programme (Supplementary Information Part 1), this group will observe the most substantial drop in GW incidence (Figure 3). On the other hand, the reduction in GW in international students is predicted to be slower and less substantial, as a majority (72\%) are from countries with no current HPV vaccination programme or with $b \mathrm{HPV}$ vaccination programmes that do not protect against GW. It was estimated that nearly half of the cases in the international travellers will be attributable to international students by 2060 . 


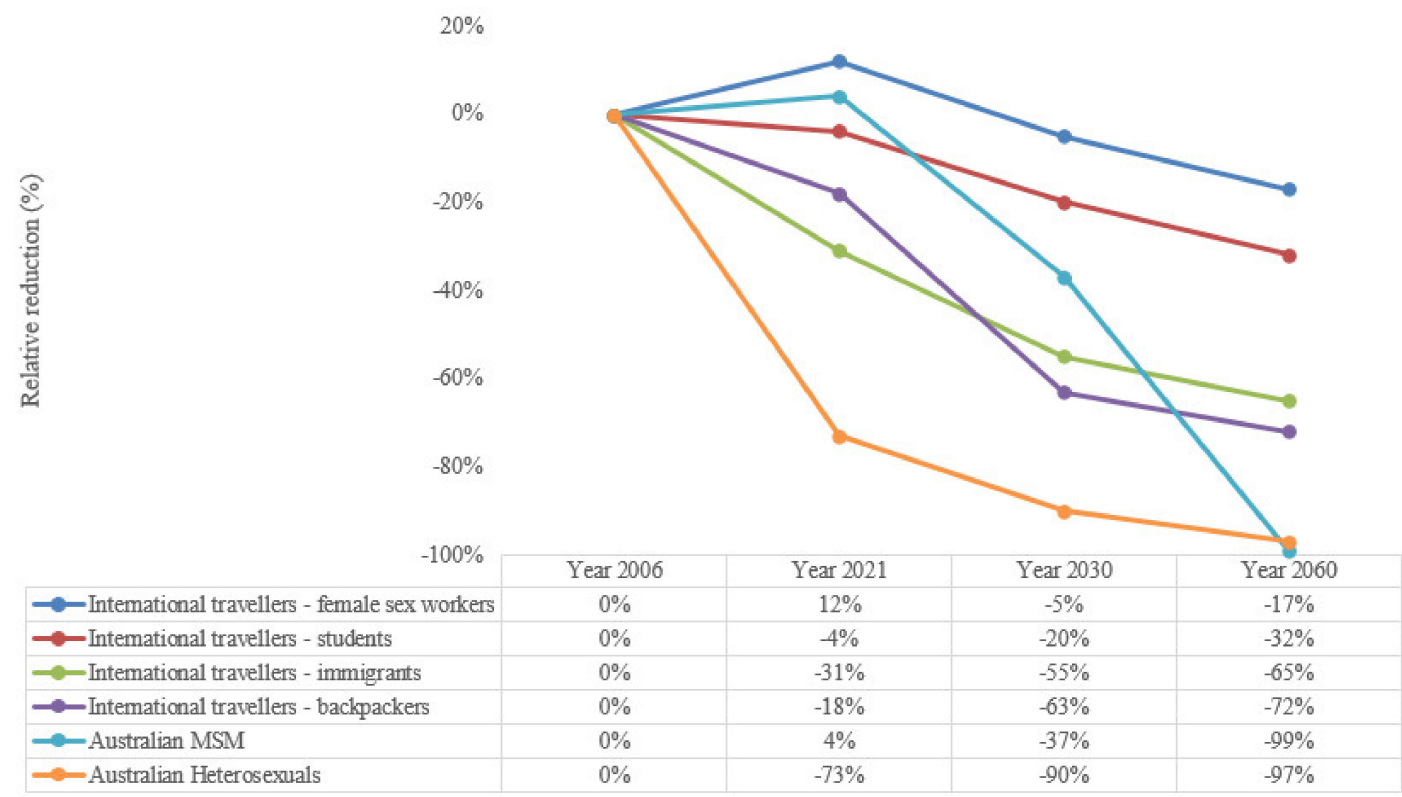

MSM: Men who have sex with men

Figure 2. Revised estimates of relative reduction in new cases of genital warts in Australia, in all populations considered, after adjusting for the ongoing transmission due to importation of genital warts, by time period.

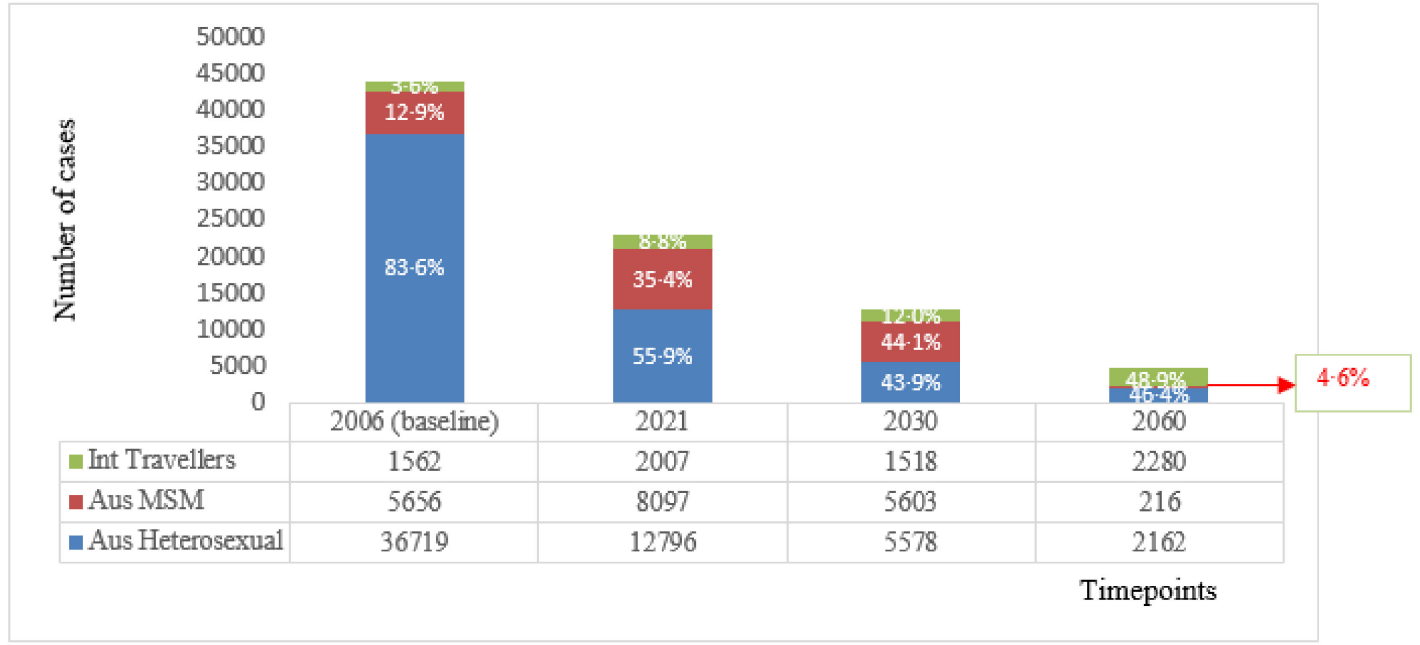

Int travellers: international travellers. Aus MSM: Australian men who have sex with men. Aus Heterosexual: Australian heterosexual population

Figure 3. Revised number and proportion of estimated new genital warts cases in Australia for timepoints 2006, 2021, 2030 and 2060, after adjusting for the ongoing transmission due to importation of genital warts, by population type.

\section{Discussion}

To the best of our knowledge, this is the first study to define GW elimination at a national level (using Australia as a case study). In the past, elimination targets of other infectious diseases have been presumably developed in consultation with experts, but often very little detail of the process is available [8]; this is the first documented instance of a Delphi study being used to define elimination of an infectious disease. Consensus was reached that with an ongoing HPV vaccination programme achieving $\geq 80 \%$ coverage in the target population, GW will be eliminated as a public health problem 
in Australia by 2060 at $\leq 1$ new GW case per 10,000 population, equivalent to a $95 \%$ reduction in GW incidence as compared to the baseline of 2006. This impact will be observed at a population level including all Australian residents and recently arrived international travellers. Consensus was also met on the need for surveillance of GW diagnoses at all primary health services that are representative of the Australian population and that this should include genotyping. Our study suggests that while major declines have already been observed in vaccine-eligible Australian-born people, population-level elimination will take several decades, partly due to GW importation from countries without a $q \mathrm{HPV}$ or $n \mathrm{HPV}$ vaccine programme.

Cervical cancer is a major HPV-related global public health problem and the aspirational goal of elimination defined by the WHO provides impetus for countries to achieve high HPV vaccination coverage using one of three available HPV vaccines. The primary purpose of HPV vaccination is to prevent cervical cancer, and while all three vaccines are highly effective in providing protection against infections with cancer causing HPV types $16 / 18$, two HPV vaccines, $q \mathrm{HPV}$ and $n \mathrm{HPV}$, also provide protection against GW caused by low-risk HPV types 6/11. The choice of vaccine for a national vaccination programme generally depends on affordability, but in some countries, such as the United Kingdom, the decision was influenced by our previous research [29] on the reductions in genitals warts achieved by using the $q \mathrm{HPV}$ vaccine [30]. In the event a country chooses to adopt the $q \mathrm{HPV}$ or the $n \mathrm{HPV}$ vaccine for their national programme, defining GW elimination thresholds will provide useful additional information to monitor the programmes' performance. The framework developed through our study for Australia could be replicated for other countries, if comprehensive epidemiological and mathematical modelling information is available in the local context.

Our HPV vaccination course completion threshold of $\geq 80 \%$ coverage necessary to reach population-level elimination in Australia, is consistent with the WHO target of $90 \%$ for female-only vaccination [7] and the $80 \%$ target specified in the Fourth Australian National STI Strategy target for adolescent HPV vaccination [31]. This vaccination threshold serves as a benchmark to reach GW elimination and does not negate the vaccination threshold set for elimination of cervical cancer, which requires high and wide-spread coverage of both HPV vaccination and cervical screening [7].

Our results suggest that interruption of endemic transmission of HPV 6/11 is not a suitable elimination definition for GW. For other infections for which elimination thresholds have been set by the WHO for interruption of endemic transmission (i.e., malaria, measles, and congenital rubella syndrome), case-based surveillance is carried out by conducting genotyping in every outbreak to differentiate endemic versus imported or import-related cases [32,33]. Such discrete geographical variations of HPV 6/11 subtypes do not exist [34-36], and therefore even if interruption of endemic HPV 6/11 is achieved in the future, distinguishing between endemic and imported cases through genotyping may not be possible.

Elimination as a public health problem is a more appropriate approach for defining GW elimination. The burden of GW in Australia prior to the introduction of $q$ HPV vaccination satisfied the essential criteria for classification of a condition as a public health problem [37,38]—namely, high burden of disease [21], loss of quality of life [39], high financial cost [21], and the feasibility to act at a community level [29]. While our results indicate that GW will be eliminated as a public health problem by year 2060 at a population level with the fastest reduction in Australian resident heterosexuals, it will be important to monitor progress in certain sub-populations that have historically been at higher risk of GW, and have not yet demonstrated significant declines in GW, such as immunocompromised individuals [40], transgender people [41], and migrant sex workers [42]. This will ensure that long-term benefits extend to all individuals in an equitable manner and that targeted interventions can be implemented where necessary.

A key finding from our study is that absolute elimination of GW in Australia is unlikely. Firstly, importation of GW caused by HPV6/11 will continue with over half the remaining cases occurring in international travellers in 2060. Of these, nearly half the cases will be attributed to international students. Currently, a majority (72\%) of Australian international students are from countries that 
either do not have an HPV vaccination programme or only have a $b \mathrm{HPV}$ vaccination programme, with China and India (both currently with no HPV vaccination programme) comprising $24 \%$ and $13 \%$ of international students, respectively [43]. Therefore, there is a need to monitor GW prevalence over time in this group of travellers to evaluate the extent to which they might undermine the impact of the Australian HPV vaccination programme.

Secondly, a small proportion of GW are caused by HPV types for which current HPV vaccines provide no direct protection. As noted, the control and elimination thresholds defined in this study were not adjusted for the contribution of GW caused by non-vaccine HPV types. The underlying assumption was that their contribution would likely be minimal or insignificant based on new evidence from a study that compared urine samples of vaccinated and unvaccinated cohorts of young girls and suggested that $q \mathrm{HPV}$ vaccination offers significant cross-protection against non-vaccine HPV types, including the majority of those that cause GW [28]. In the light of this evidence and in the absence of evidence of type replacement [44], we concluded that GW attributable to non-vaccine HPV types may also decline. Nevertheless, there is a possibility that we have underestimated the impact of non-vaccine HPV types as HPV prevalence may be lower in urine samples than cervical or vaginal samples [45-47]. To truly understand the pathogenesis and causality of non-vaccine HPV types in GW in the post-vaccination era, a prospective study with adequate power is required to detect specific HPV genotypes in GW.

We conservatively adjusted the control milestone and threshold to account for the impact of ongoing chains of transmission in Australia due to importation of HPV types that cause GW. The underlying assumption was that population-level herd protection would not be reached by years 2021 and 2030 and therefore transmission due to importation will continue. One way of addressing this question is to calculate $\mathrm{R}_{\text {eff }}$ for HPV 6/11 and then use this to estimate the probability that a chain of transmission due to importation will occur. This is outside the scope of this study; however, it is the subject of ongoing work by the authors. We did not adjust the 2060 elimination threshold of 95\% relative reduction in GW incidence as the HPV vaccination coverage is likely to increase over time, both in Australia and globally, and the importance of importation is likely to be diminished accordingly. This is particularly important in terms of the anticipated increase in vaccination coverage in low- and middle-income countries where HPV vaccination might become more affordable due to: (a) technology transfers of existing vaccines to manufacturers in middle-income countries [48,49]; and (b) moving to single-dose vaccination, which is currently being evaluated in ongoing studies [50].

Our study has some limitations. First, we compromised the anonymity of experts in the workshop as this was necessary to expedite the consensus building process. In doing so, we may have introduced a degree of 'bandwagon effect', a phenomenon whereby those with strong opinions may sway the opinions of others [51]. To counter this effect, we provided an opportunity for anonymous individual scoring in the third online round so that the experts could reflect on and score the revised items without peer pressure. Second, where information was not available for baseline GW incidence and relative reduction of GW incidence, we used baseline GW prevalence and relative reduction in incidence or prevalence of HPV 6/11 as proxies (Supplementary Information part 1). In doing so, we might have overestimated the number of new GW cases and the estimated relative reductions in some of the sub-populations.

Our study also has several strengths and fulfilled important factors that determine the validity of the Delphi technique. These include: (a) selection of a heterogenous panel, with expertise across various areas of the health sector [52]; (b) achievement of a high response rate [53]; (c) retention of those experts that held outlying opinions (important due to their potential for challenging conventional thinking) [52]; and (d) careful attention to content analysis and interpretation of the survey data [19,54] that took into account the qualitative feedback collected during each round and the two plenary sessions. The last point is particularly important, as our study took into consideration the richness and depth found in 'live' group discussion, which is often missing in conventional Delphi studies. 
In conclusion, we defined thresholds for elimination of GW at a national level, using Australia as the case study, the first country in the world to implement a nationally funded $q \mathrm{HPV}$ vaccination programme [55]. On the assumption that Australia maintains its high HPV vaccination coverage, GW elimination defined through this study will serve as a valuable tool for programme impact evaluation. However, questions remain around the potential impact of non-vaccine HPV types and the ongoing chains of transmission due to importation. This means that the control and elimination thresholds defined by this study may need to be adjusted in the future subject to research that may provide new information. As more countries roll out HPV vaccination programmes, the framework developed through this study could be used to help guide the development of GW elimination thresholds in other settings.

Supplementary Materials: The following are available online at http://www.mdpi.com/2076-393X/8/2/316/s1, Supplementary Information Part 1: Development of the proposed control and elimination thresholds for the Delphi Workshop, Supplementary Information Part 2:Work undertaken for questionnaire revision as per experts' feedback for the online round of the Delphi process, Table S1: Values for parameters used in our calculations of the elimination-related thresholds for the Australian resident population (heterosexual and MSM), Table S2: Values for parameters used in our calculations of the elimination-related thresholds for international travellers (backpackers, newly commencing international student, newly arriving migrants and female sex workers), Table S3: Percentage distribution of backpackers visiting Australia, by home country and availability of $q \mathrm{HPV}$ vaccination program, Table S4: Percentage distribution of newly commencing international students in Australia, by home country and availability of $q \mathrm{HPV}$ vaccination program, Table S5: Percentage distribution of newly arriving immigrants, by home country and availability of $q$ HPV vaccination program, Table S6: Percentage distribution of newly arriving international female sex workers in Australia, by home country and availability of $q \mathrm{HPV}$ vaccination program; Table S7: Pre-vaccination incidence rates of genital warts in young people aged 20-24 years, by country, Table S8: Pre-vaccination incidence rates of genital warts in people aged <30 years, by sex, Table S9: Pre-vaccination incidence rates of genital warts in people aged 20-40 years, by sex, Table S10: International female sex workers: Prevalence of genital warts in female sex worker population in home country, Table S11: Equations for calculations of new genital warts cases in the sub-groups of international travellers, for each time point (example Backpackers' sub-group); Table S12: Estimates presented at the Delphi workshop for number and relative reduction in new genital warts consults in Australia, by sub-population type, Table S13: Questionnaire and results of Round 1 of the Delphi Workshop.

Author Contributions: L.K., S.M., R.J.G. conceived the idea for the study. L.K. developed the initial study proposal, study design, ethics application, performed literature review, background calculations and drafted the study questionnaire. D.A.M., D.G.R., B.D., S.M. and R.J.G. provided extensive consultation in the development of study questionnaire. D.A.M., D.G.R., BD., S.M. and R.J.G. facilitated the small group discussions during the workshop. All authors contributed to revision of literature provided to the panel. B.D., S.M. and R.J.G. provided PhD supervision. L.K. performed data analysis. L.K., S.M. and R.J.G. participated in data interpretation. L.K. wrote the first draft of the manuscript. All authors contributed to subsequent drafts. All authors have read and agreed to the published version of the manuscript.

Funding: The lead author was supported through an Australian Government Research Training Program Scholarship. In addition, Seqirus provided unconditional funds to support the Delphi Workshop. The funders had no role in study design, data collection and analysis, decision to publish, or preparation of the manuscript.

Acknowledgments: The authors are grateful to the panel of experts who participated in the study. Their participation does not imply that they agree with the results and conclusions from the study. The following experts (in alphabetical order) participated in at least one of the rounds of the Delphi process and agreed to be identified: Amy Bright (Australian Government, Department of Health), Julia Brotherton (VCS Population Health), Karen Canfell (Cancer Council NSW), Eric Chow (Melbourne Sexual Health Centre \& Monash University), Suzanne M Garland (Centre for Women's Infectious Diseases Research \& University of Melbourne), Richard Gray (The Kirby Institute, UNSW Sydney), Andrew Grulich (The Kirby Institute, UNSW Sydney), Jane Hocking (Centre for Epidemiology and Biostatistics, Melbourne School of Population and Global Health, University of Melbourne), Barbara Kuter (Merck \& Co.), Matthew Law (The Kirby Institute, UNSW Sydney), Bette Liu (School of Public Health and Community Medicine, UNSW Sydney), Kristine Macartney (National Centre for Immunisation Research and Surveillance \& The University of Sydney Children's Hospital Westmead Clinical School), Raina MacIntyre (The Kirby Institute, UNSW Sydney), Helen Marshall (Vaccinology and Immunology Research Trials Unit, Women's and Children's Hospital), Kate Simms (Cancer Council NSW), Rachel Skinner (Children's Hospital Westmead \& University of Sydney), Megan Smith (Cancer Council NSW), James Wood (School of Public Health and Community Medicine, UNSW Sydney). The authors would also like to acknowledge the contributions made by the participants of the pilot study, from the Kirby Institute, UNSW Sydney: Hamish McManus, Praveena Gunaratnam, Muhammad Jamil, Amy Kwon, Sophie Phelan, Kate Whitford, Prital Patel and Hawa Camara. The authors also thank John M Kaldor for moderating the plenary sessions during the Delphi Workshop, Hamish McManus for his guidance in statistical analyses, and Prital Patel, Jane Costello and Morgan Stewart for their administrative support in conducting the Delphi workshop. 
Conflicts of Interest: L.K., B.D., D.G.R., S.M., R.J.G. report grants from Seqiris, during the conduct of the study and grants from Australian Government Department of Health and grants from Seqirus, outside the submitted work; D.A.M. reports grants and other support from Seqirus (bioCSL), and non-financial support from MSD outside the submitted work.

\section{References}

1. Forman, D.; de Martel, C.; Lacey, C.J.; Soerjomataram, I.; Lortet-Tieulent, J.; Bruni, L.; Vignat, J.; Ferlay, J.; Bray, F.; Plummer, M.; et al. Global burden of human papillomavirus and related diseases. Vaccine 2012, 30, F12-F23. [CrossRef] [PubMed]

2. Lee, L.-Y.; Garland, S.M. Human papillomavirus vaccination: The population impact. F1000Research 2017, 6, 866. [CrossRef] [PubMed]

3. World Health Organization. Immunization, Vaccines and Biologicals-Human Papillomavirus (HPV). 2018. Available online: https://www.who.int/immunization/diseases/hpv/en/ (accessed on 26 September 2019).

4. Brown, D.R.; Schroeder, J.M.; Bryan, J.T.; Stoler, M.H.; Fife, K.H. Detection of multiple human papillomavirus types in Condylomata acuminata lesions from otherwise healthy and immunosuppressed patients. J. Clin. Microbiol. 1999, 37, 3316-3322. [CrossRef] [PubMed]

5. World Health Organization. Global Market Study HPV. 2018. Available online: https: //www.who.int/immunization/programmes_systems/procurement/mi4a/platform/module2/WHO_ HPV_market_study_public_summary.pdf (accessed on 10 November 2019).

6. International Agency for Research on Cancer, World Health Organization. Estimated Cancer Incidence, Mortality and Prevalence Worldwide in 2018. Cervical Cancer Fact Sheet. 2018. Available online: https://gco.iarc.fr/today/data/factsheets/cancers/23-Cervix-Uteri-fact-sheet.pdf (accessed on 25 November 2019).

7. World Health Organization. Draft: Global Strategy towards the Elimination of Cervical Cancer as a Public Health Problem; World Health Organization: Geneva, Switzerland, 2019.

8. World Health Organization. Global Health Sector Strategy on Sexually Transmitted Infections 2016-2021-towards Ending STIs; World Health Organization: Geneva, Switzerland, 2016.

9. Drolet, M.; Bénard, É.; Pérez, N.; Brisson, M.; HPV Vaccination Impact Study Group. Population-level impact and herd effects following the introduction of human papillomavirus vaccination programmes: Updated systematic review and meta-analysis. Lancet 2019, 394, 497-509. [CrossRef]

10. Garland, S.M.; Skinner, S.R.; Brotherton, J.M. Adolescent and young adult HPV vaccination in Australia: Achievements and challenges. Prev. Med. 2011, 53, S29-S35. [CrossRef] [PubMed]

11. Brill, D. Australia launches national scheme to vaccinate boys against HPV. BMJ 2013, 346, f924. [CrossRef] [PubMed]

12. Kirby Institute. HIV, Viral Hepatitis and Sexually Transmissible Infections in Australia: Annual Surveillance Report 2018; Kirby Institute: UNSW Sydney, Australia, 2018.

13. World Health Organization. Generic Framework for Control, Elimination and Eradication of Neglected Tropical Diseases; World Health Organization: Geneva, Switzerland, 2016.

14. Korostil, I.A.; Ali, H.; Guy, R.J.; Donovan, B.; Law, M.G.; Regan, D.G. Near elimination of genital warts in Australia predicted with extension of human papillomavirus vaccination to males. Sex. Transm. Dis. 2013, 40, 833-835. [CrossRef]

15. Zhang, L.; Regan, D.G.; Ong, J.J.; Gambhir, M.; Chow, E.P.F.; Zou, H.; Law, M.; Hocking, J.; Fairley, C.K. Targeted human papillomavirus vaccination for young men who have sex with men in Australia yields significant population benefits and is cost-effective. Vaccine 2017, 35, 4923-4929. [CrossRef]

16. Brisson, M.; Bénard, É.; Drolet, M.; Bogaards, J.A.; Baussano, I.; Vänskä, S.; Jit, M.; Boily, M.C.; Smith, M.A.; Berkhof, J.; et al. Population-level impact, herd immunity, and elimination after human papillomavirus vaccination: A systematic review and meta-analysis of predictions from transmission-dynamic models. Lancet Public Health 2016, 1, e8-e17. [CrossRef]

17. Ball, S.L.; Winder, D.M.; Vaughan, K.; Hanna, N.; Levy, J.; Sterling, J.C.; Stanley, M.A.; Goon, P.K.C. Analyses of human papillomavirus genotypes and viral loads in anogenital warts. J. Med. Virol. 2011, 83, 1345-1350. [CrossRef] 
18. Hawkins, M.G.; Winder, D.M.; Ball, S.L.R.; Vaughan, K.; Sonnex, C.; Stanley, M.A.; Sterling, J.C.; Goon, P.K.C. Detection of specific HPV subtypes responsible for the pathogenesis of condylomata acuminata. Virol. J. 2013, 10, 137. [CrossRef]

19. Hasson, F.; Keeney, S.; McKenna, H. Research guidelines for the Delphi survey technique. J. Adv. Nurs. 2000, 32, 1008-1015. [PubMed]

20. Van Zolingen, S.J.; Klaassen, C.A. Selection processes in a Delphi study about key qualifications in senior secondary vocational education. Technol. Forecast. Soc. Chang. 2003, 70, 317-340. [CrossRef]

21. Pirotta, M.; Stein, A.N.; Conway, E.L.; Harrison, C.; Britt, H.; Garland, S.M. Genital warts incidence and healthcare resource utilisation in Australia. Sex. Transm. Infect. 2010, 86, 181-186. [CrossRef]

22. Manhart, L.E.; Koutsky, L.A. Do condoms prevent genital HPV infection, external genital warts, or cervical neoplasia? A meta-analysis. Sex. Transm. Dis. 2002, 29, 725-735. [CrossRef] [PubMed]

23. Jin, F.; Prestage, G.P.; Kippax, S.C.; Pell, C.M.; Donovan, B.; Templeton, D.J.; Kaldor, J.; Grulich, A.E. Risk factors for genital and anal warts in a prospective cohort of HIV-negative homosexual men: The HIM study. Sex. Transm. Dis. 2007, 34, 488-493. [CrossRef]

24. Renshaw, L.; Kim, J.; Fawkes, J.; Jeffreys, E. Migrant Sex Workers in Australia. Research and Public Policy No. 131; Australian Institute of Criminology: Canberra, Australia, 2015.

25. Hughes, K.; Downing, J.; Bellis, M.A.; Dillion, P.; Copeland, J. The sexual behaviour of British backpackers in Australia. Sex. Transm. Infect. 2009, 85, 477-482. [CrossRef]

26. Rosenthal, D.A.; Russell, J.; Thomson, G. The health and wellbeing of international students at an Australian university. High. Educ. 2008, 55, 51-57. [CrossRef]

27. Australian Bureau of Statistics. 3222.0-Population Projections, Australia, 2012 (base) to 2101. 2013. Available online: http://www.abs.gov.au/ausstats/abs@.nsf/lookup/3222.0Media\%20Release12012\%20(base)\%20to\% 202101 (accessed on 2 October 2019).

28. Feiring, B.; Laake, I.; Christiansen, I.K.; Hansen, M.; Stålcrantz, J.; Ambur, O.H.; Magnus, P.; Jonassen, C.M.; Trogstad, L. Substantial decline in prevalence of vaccine-type and nonvaccine-type human papillomavirus (HPV) in vaccinated and unvaccinated girls 5 years after implementing HPV vaccine in Norway. J. Infect. Dis. 2018, 218, 1900-1910. [CrossRef]

29. Donovan, B.; Franklin, N.; Guy, R.J.; Grulich, A.E.; Ali, H.; Wand, H.; Fairley, C.K. Quadrivalent human papillomavirus vaccination and trends in genital warts in Australia: Analysis of national sentinel surveillance data. Lancet Infect. Dis. 2011, 11, 39-44. [CrossRef]

30. Denis Campbell. Genital Warts Vaccination to be Offered to Schoolgirls. Guardian 2011. Available online: https://www.theguardian.com/society/2011/nov/24/genital-warts-vaccination-offered-schoolgirls (accessed on 10 March 2020).

31. Australian Government Department of Health. Fourth National Sexually Transmissible Infections Strategy 2018-2022. 2018. Available online: https:/www1.health.gov.au/internet/main/publishing.nsf/Content/ohpbbvs-1/\$File/STI-Fourth-Nat-Strategy-2018-22.pdf (accessed on 26 September 2019).

32. World Health Organization. A Framework for Malaria Elimination; World Health Organization: Geneva, Switzerland, 2017.

33. World Health Organization. Framework for verifying elimination of measles and rubella. Wkly. Epidemiol. Rec. 2013, 88, 89-98.

34. Danielewski, J.A.; Garland, S.M.; McCloskey, J.; Hillman, R.J.; Tabrizi, S.N. Human papillomavirus type 6 and 11 genetic variants found in 71 oral and anogenital epithelial samples from Australia. PLoS ONE 2013, 8, e63892. [CrossRef] [PubMed]

35. Heinzel, P.A.; Chan, S.-Y.; Ho, L.; O'Connor, M.; Balaram, P.; Campo, M.S.; Fujinaga, K.; Kiviat, N.; Kuypers, J.; Pfister, H. Variation of human papillomavirus type 6 (HPV-6) and HPV-11 genomes sampled throughout the world. J. Clin. Microbiol. 1995, 33, 1746-1754. [CrossRef] [PubMed]

36. Jelen, M.M.; Chen, Z.; Kocjan, B.J.; Burt, F.J.; Chan, P.K.S.; Chouhy, D.; Combrinck, C.E.; Coutlée, F.; Estrade, C.; Ferenczy, A.; et al. Global genomic diversity of human papillomavirus 6 based on 724 isolates and 190 complete genome sequences. J. Virol. 2014, 88, 7307-7316. [CrossRef]

37. Vinicor, F. Is diabetes a public-health disorder? Diabetes Care 1994, 17, 22-27.

38. Schoolwerth, A.C.; Engelgau, M.M.; Rufo, K.H.; Vinicor, F.; Hostetter, T.H.; Chianchiano, D.; McClellan, W.M.; Warnock, D.G. Chronic Kidney Disease: A Public Health Problem That Needs a Public Health Action Plan. Prev. Chronic Dis. 2006, 3, A57. 
39. Pirotta, M.; Ung, L.; Stein, A.; Conway, E.L.; Mast, T.C.; Fairley, C.K.; Garland, S. The psychosocial burden of human papillomavirus related disease and screening interventions. Sex. Transm. Infect. 2009, 85, 508-513. [CrossRef]

40. Conley, L.J.; Ellerbrock, T.V.; Bush, T.J.; Chiasson, M.A.; Sawo, D.; Wright, T.C. HIV-1 infection and risk of vulvovaginal and perianal condylomata acuminata and intraepithelial neoplasia: A prospective cohort study. Lancet 2002, 359, 108-113. [CrossRef]

41. Hounsfield, V.L.; Freedman, E.; McNulty, A.; Bourne, C. Transgender people attending a Sydney sexual health service over a 16-year period. Sex. Health 2007, 4, 189-193. [CrossRef]

42. O'Connor, C.; Berry, G.; Rohrsheim, R.; Donovan, B. Sexual health and use of condoms among local and international sex workers in Sydney. Sex. Transm. Infect. 1996, 72, 47-51. [CrossRef]

43. Department of Education and Training Australian Government. International Student Data 2017; Basic Pivot Table 2002 Onwards. 2017. Available online: https://internationaleducation.gov.au/research/InternationalStudent-Data/Pages/InternationalStudentData2017.aspx\#Pivot_Table (accessed on 26 September 2019).

44. Tota, J.E.; Jiang, M.; Ramanakumar, A.V.; Walter, S.D.; Kaufman, J.S.; Coutlée, F.; Richardson, H.; Burchell, A.N.; Kouchik, A.; Maryand, M.H.; et al. Epidemiologic evaluation of human papillomavirus type competition and the potential for type replacement post-vaccination. PLoS ONE 2016, 11, e0166329. [CrossRef] [PubMed]

45. Enerly, E.; Olofsson, C.; Nygård, M. Monitoring human papillomavirus prevalence in urine samples: A review. Clin. Epidemiol. 2013, 5, 67-79. [CrossRef] [PubMed]

46. Vorsters, A.; Micalessi, I.; Bilcke, J.; Ieven, M.; Bogers, J.; Van, D.P. Detection of human papillomavirus DNA in urine. A review of the literature. Eur. J. Clin. Microbiol. Infect. Dis. 2012, 31, 627-640. [CrossRef] [PubMed]

47. Sehgal, A.; Gupta, S.; Parashari, A.; Sodhani, P.; Singh, V. Urine HPV-DNA detection for cervical cancer screening: Prospects and prejudices. J. Obstet. Gynaecol. 2009, 29, 583-589. [CrossRef] [PubMed]

48. Padmanabhan, S.; Amin, T.; Sampat, B.; Cook-Deegan, R.; Chandrasekharan, S. Intellectual property, technology transfer and manufacture of low-cost HPV vaccines in India. Nat. Biotechnol. 2010, 28, 671-678. [CrossRef] [PubMed]

49. Baker, M.L.; Figueroa-Downing, D.; Chiang, E.D.D.O.; Villa, L.; Baggio, M.L.; Eluf-Neto, J.; Bednarczyk, R.A.; Evans, D.P. Paving pathways: Brazil's implementation of a national human papillomavirus immunization campaign. Rev. Panam. Salud Publica 2015, 38, 163-166.

50. Brotherton, J.M.; Budd, A.; Rompotis, C.; Barlett, N.; Malloy, M.J.; Andersen, R.L.; Coulter, K.A.R.; Couvee, P.W.; Steel, N.; Ward, G.H.; et al. Is one dose of human papillomavirus vaccine as effective as three? A national cohort analysis. Papillomavirus Res. 2019, 8, 100177. [CrossRef]

51. Webler, T.; Levine, D.; Rakel, H.; Renn, O. A novel approach to reducing uncertainty: The group Delphi. Technol. Forecast. Soc. Chang. 1991, 39, 253-263. [CrossRef]

52. Bolger, F.; Wright, G. Improving the Delphi process: Lessons from social psychological research. Technol. Forecast. Soc. Chang. 2011, 78, 1500-1513. [CrossRef]

53. Beretta, R. A critical review of the Delphi technique. Nurs. Res. 1996, 3, 79-89. [CrossRef]

54. Kennedy, H.P. A model of exemplary midwifery practice: Results of a Delphi study. J. Midwifery Women Health 2000, 45, 4-19. [CrossRef]

55. Hall, M.T.; Simms, K.T.; Lew, J.-B.; Smith, M.A.; Brotherton, J.M.; Saville, M.; Frazer, I.H.; Canfell, K. The projected timeframe until cervical cancer elimination in Australia: A modelling study. Lancet Public Health 2019, 4, e19-e27. [CrossRef]

(C) 2020 by the authors. Licensee MDPI, Basel, Switzerland. This article is an open access article distributed under the terms and conditions of the Creative Commons Attribution (CC BY) license (http://creativecommons.org/licenses/by/4.0/). 